Jurnal Keperawatan Silampari

Volume 4, Nomor 1, Desember 2020

e-ISSN: 2581-1975

p-ISSN: 2597-7482

DOI: https://doi.org/10.31539/jks.v4i1.1281

\title{
ANDRA'S NURSING INFORMATIC SYSTEM APPLICATION (ANNISA) DALAM UPAYA MENINGKATKAN PENGETAHUAN PERAWAT TENTANG DOKUMENTASI KEPERAWATAN
}

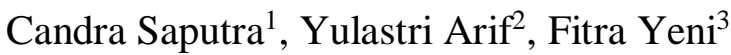 \\ Sekolah Tinggi Ilmu Kesehatan Payung Negeri Pekanbaru ${ }^{1}$ \\ Universitas Andalas ${ }^{2,3}$ \\ candra.saputra@payungnegeri.ac.id ${ }^{1}$
}

\begin{abstract}
ABSTRAK
Tujuan penelitian ini untuk mengetahui efektivitas pengembangan ANNISA terhadap pengetahuan perawat tentang dokumentasi keperawatan. Metode ini menggunakan penelitian kuantitatif dengan desain quasi eksperimen dan pendekatan time series non equievalent control group design. Hasil penelitian ada perbedaan pengukuran pengetahuan perawat tentang dokumentasi keperawatan kelompok intervensi sebelum intervensi dengan mengukur posttest-1 dengan $\mathrm{p}$ value $=0,000$. Ada perbedaan pengetahuan perawat tentang dokumentasi keperawatan antara kelompok intervensi dan kelompok kontrol dalam pengukuran posttest-1 dan posttest-2 setelah intervensi penggunaan ANNISA dengan $p$ value $=0,000$. Ada peningkatan perbedaan pengetahuan perawat tentang dokumentasi keperawatan dari pretest, postest-1 dan posttest-2 pengukuran setelah penggunaan ANNISA pada kelompok intervensi dan kelompok kontrol dengan $p$ value $=0,000$. Simpulan, pengembangan ANNISA memiliki efek pada peningkatan pengetahuan perawat tentang dokumentasi keperawatan.
\end{abstract}

Kata Kunci: ANNISA, Dokumentasi Keperawatan, Pengetahuan

\begin{abstract}
This study aimed to determine the effectiveness of ANNISA development on nurses' knowledge of nursing documentation. This method uses quantitative research with a quasi-experimental design and a time series approach non-equivocal control group design. The study results were there were differences in the measurement of nurses' knowledge about nursing documentation in the intervention group before the intervention by measuring posttest-1 with p-value $=0.000$. There were differences in nurses' experience about nursing documentation between the intervention group and the control group in the posttest-1 and posttest-2 measurements after the intervention using ANNISA with $p$-value $=0,000$. There was an increase in differences in nurses knowledge about nursing documentation from the pretest, posttest-1, and posttest-2 measurements after using ANNISA in the intervention group and the control group with $p$-value $=0.000$. In conclusion, ANNISA development affects increasing the knowledge of nurses about nursing documentation
\end{abstract}

Keywords: ANNISA, Nursing Documentation, Knowledge 


\section{PENDAHULUAN}

Perawat memiliki peran penting dalam melakukan dokumentasi keperawatan. Di Korea Selatan menunjukkan yang melakukan dokumentasi keperawatan terdiri dari perawat pelaksana sebesar $40,4 \%$, ketua tim perawat 38,0\%, kepala keperawatan $16,6 \%$ dan perawat administrasi dan perawat ruang infeksi masing-masing 2,5\% (Lee et al., 2019). Sedangkan di Indonesia dokumentasi keperawatan dilakukan oleh perawat dimana 57,2\% kegiatan perawat adalah melakukan dokumentasi keperawatan di pelayanan primer dan 46,8\% kegiatan di rumah sakit perawat melaksanakan dokumentasi keperawatan (Saputra, 2018; Saputra et al., 2019). Hal ini memberikan tuntutan terhadap pentingnya pelaksanaan dokumentasi keperawatan.

Pelaksanaan dokumentasi keperawatan yang dilakukan oleh perawat disebabkan oleh berbagai faktor. Di Malaysia menunjukkan bahwa penggunaan teknologi informasi sangat membantu dalam meningkatkan pengetahuan perawat tentang dokumentasi keperawatan dan di Amerika menunjukkan bawah dokumentasi disebabkan oleh faktor pengetahuan perawat sebesar 62\% (Karp, et al, 2019; Rojjanasrirat, 2018). Di Indonesia pengetahuan perawat tentang dokumentasi masih rendah yang disebabkan oleh faktor pendidikan, kemampuan dan keterampilan serta penggunaan teknologi informasi (Kamil et al., 2018). Sehingga upaya yang dapat dilakukan untuk meningkatkan pengetahuan tentang dokumentasi keperawatan adalah melalui perubahan dokumentasi berbasis kertas ke berbasis elektronik dimana menyediakan layanan informasi tentang dokumentasi pada platform yang digunakan (Oreofe \& Oyenike, 2018; Salameh, et al, 2019).

Penggunaan dokumentasi keperawatan berbasis elektronik sangat efektif bagi perawat (Cassano, 2018). Hal ini sejalan dengan hasil penelitian Padila et al., (2018) dimana hasil penelitian terdapat rancangan sistem program yang memiliki keunggulan untuk mengirim data pelaporan dokumentasi medis pasien yang meliputi keluhan utama, tipe penyakit yang dirasakannya (ringan, sedang dan berat), visualisasi data secara image, sound dan text, bahkan video dapat digunakan sebagai alat detektor kesehatan pasien berbasis digital melalui video mail, dan riwayat kesehatan keluarga dengan teknik multimedia medical records yang terkoneksi dengan pusat layanan kesehatan RSUD. Dr. M. Yunus Bengkulu. Di amerika menunjukkan $71 \%$ sudah mampu melakukan dokumentasi keperawatan menggunakan teknologi informasi dan $71,98 \%$ perawat setuju dan sudah memahami menggunakan dokumentasi berbasis elektronik untuk meningkatkan pengetahuan dan kemampuan tentang dokumentasi keperawatan (Chand \& Sarin, 2019; McNicol, et al, 2018). Di Indonesia, dokumentasi keperawatan mencapai $71,2 \%$ dan $73,2 \%$ yang dilaksanakan masing-masing di rumah sakit dan di tingkat pelayanan primer (Pratama et al., 2018; Saputra \& Arif, 2019). Proses pelaksanaan dokumentasi berbasis elektronik tentunya harus sesuai dengan standar dokumentasi keperawatan dan terminology dalam pelaksanaan dokumentasi keperawatan.

Terminology yang digunakan dalam praktik pendokumentasi keperawatan umumnya adalah menggunakan NNN (Nanda-I, NIC \& NOC) Linkage. Di Afrika, penerapan terminology NNN Linkage sudah dilaksanakan di tingkat pelayanan primer (Omonigho, 2019). Sedangkan di Nigeria penggunaan terminology NNN Lingkage dalam praktik dokumentasi masih dipengaruhi oleh faktor pengetahuan $(73,8 \%)$, serta $66,7 \%$ perawat di Nigeria setuju penggunaan terminology NNN Linkage dalam praktik dokumentasi keperawatan (Olatubi, et al, 2019). Sedangkan di Indonesia penggunaan terminology dalam praktik dokumentasi keperawatan berbasis elektronik sudah 
diterapkan di berbagai rumah sakit maupun di tingkat pelayanan primer (Saraswasta \& Hariyati, 2019). Penggunaan terminology NNN Linkage dalam praktik dokumentasi keperawatan berbasis elektronik akan lebih meningkatkan pengetahuan dan pemahaman perawat tentang proses dokumentasi keperawatan (Chae et al., 2020).

Model sistem informasi keperawatan pada saat sekarang sudah banyak berkembang. Sistem informasi keperawatan di tatanan pelayanan puskesmas yang dikembangkan adalah ANNISA. ANNISA merupakan singkatan dari Andra's Nursing Informatic System Application yaitu suatu model sistem informasi keperawatan yang digunakan sebagai bentuk instrumen dokumentasi keperawatan ditatanan praktik keperawatan komunitas yang berorientasi pada nomenklatur NNN Linkage. Pengembangan ini digunakan pada semua tahapan dokumentasi asuhan keperawatan. Aspek dokumentasi asuhan keperawatan meliputi: pengkajian, diganosa, intervensi, implementasi berdasarkan lima strategi intervensi keperawatan komunitas dan evaluasi (Giacomo \& Santin, 2019; Peltonen et al., 2019).

Data yang didapat di puskesmas se-kota pekanbaru menunjukkan bahwa dokumentasi asuhan keperawatan di Puskesmas belum ada. Data menunjukkan 9 dari 10 perawat mengemukakan ketidakmampuan untuk melakukan dokumentasi asuhan keperawatan. Sejalan dengan hal tersebut Kepala Dinas Kesehatan Kota pekanbaru juga mengungkapkan bahwa puskesmas juga belum memiliki laporan dokumentasi asuhan keperawatan. Penerapan dokumentasi asuhan keperawatan berbasis elektronik di wilayah kerja Dinas Kesehatan Kota Pekanbaru juga belum ada. Seluruh puskesmas yang ada di kota pekanbaru dilaksanakan dengan menggunakan catatan kertas. Tentunya hal ini akan menyebabkan catatan yang tidak lengkap dan cenderung mengalami kesalahan dalam pencatatan.

Tantangan yang paling utama adalah melakukan perubahan dalam bentuk dokumentasi berbasis kertas ke dokumentasi berbasis komputerisasi. Upaya tersebut menjadi fokus peneliti untuk mampu mengembangkan suatu sistem informasi dengan mengedepankan standar asuhan keperawatan yang ada di pelayanan primer sesuai dengan tugas perawat kesehatan masyarakat. Tentunya apabila masalah tersebut dapat dicapai, pengembangan sistem informasi keperawatan yang terintegrasi merupakan strategi yang utama dalam memudahkan perawat dalam melaksanakan dokumentasi asuhan keperawatan. Adapun fokus lain dalam proses penelitian ini adalah agar perawat dapat menggunakan aplikasi ANNISA sebagai salah satu model aplikasi dokumentasi berbasis elektronik dalam meningkatkan praktik dokumentasi keperawatan sehingga dokumentasi keperawatan dapat berkualitas dapat tercapai sesuai standar praktik dokumentasi keperawatan.

\section{METODE PENELITIAN}

Jenis penelitian yang dilakukan adalah penelitian kuantatif dengan menggunakan desain penelitian adalah Eksperimental Semu (Quasy eskperiment). Pendekatan yang digunakan dalam penelitian ini adalah dengan menggunakan rancangan penelitian Time Series Non Equevalent Control Group Design. Penelitian ini dilaksanakan di seluruh puskesmas se-kota Pekanbaru pada tanggal 24 November 2018 sampai dengan 12 Maret 2019. Teknik sampling yang digunakan dalam penelitian ini adalah proportional random sampling. Sampel dalam penelitian ini adalah perawat yang bekerja di puskesmas seKota Pekanbaru dengan jumlah sampel yaitu sebanyak 48 perawat pada kelompok intervensi dan 48 perawat pada kelompok kontrol. Adapun karakteristik sampel yaitu 
perawat perkesmas, perawat yang bersedia menjadi responden dan perawat yang melakukan kunjungan keluarga binaan.

Alat pengumpulan data dalam penelitian ini menggunakan kuesioner pertanyaan tertutup pada masing-masing variabel. Alat ukur atau instrument yang digunakan adalah kuesioner pengetahuan perawat tentng dokumentasi keperawatan. Langkah-langkah penelitian terdiri dari tahap persiapan, tahap pelaksanaan yang terdiri dari tahap identifikasi kebutuhan, pengembangan model ANNISA dan tahap uji coba dan tahap akhir yaitu tahap pengujian model ANNISA terhadap pengetahuan perawat tentang dokumentasi keperawatan di tempat penelitian. Teknik analisa data yang digunakan adalah analisa data univariat untuk mendeskripsikan distribusi variabel, analisa bivariat dengan menggunakan uji statistik pair $t$ test dan independent $t$ test serta analisis multivariat dengan menggunakan uji statistik GLM-RM (Generalized Linier ModelsRepeated Measure)

\section{HASIL PENELITIAN}

Tabel. 1

Distribusi Frekuensi Karakteristik Responden pada Kelompok Intervensi dan Kelompok Kontrol ( $\mathrm{N}=96)$

\begin{tabular}{|c|c|c|c|c|}
\hline \multirow{2}{*}{ KarakteristikResponden } & \multicolumn{2}{|c|}{ Eksperimen } & \multicolumn{2}{|c|}{ Kontrol } \\
\hline & $\mathrm{f}$ & $\%$ & $\mathrm{f}$ & $\%$ \\
\hline \multicolumn{5}{|l|}{ Umur Perawat } \\
\hline a. DewasaAwal (26 - 35 tahun) & 23 & 47,9 & 26 & 54,2 \\
\hline b. DewasaAkhir (36 - 45 tahun) & 12 & 25,0 & 12 & 25,0 \\
\hline c. UsiaPertengahan (46 - 59 tahun) & 13 & 27,1 & 10 & 20,8 \\
\hline \multicolumn{5}{|l|}{ Jenis Kelamin } \\
\hline a. Laki-Laki & 21 & 43,8 & 23 & 47,9 \\
\hline b. Perempuan & 27 & 56,3 & 25 & 52,1 \\
\hline \multicolumn{5}{|l|}{ Pendidikan } \\
\hline a. D.3 & 22 & 45,8 & 24 & 50,0 \\
\hline b. $\mathrm{S} 1$ & 26 & 54,2 & 24 & 50,0 \\
\hline \multicolumn{5}{|l|}{ Masa Kerja } \\
\hline a. $\quad<5$ Tahun & 22 & 45,8 & 21 & 43,8 \\
\hline b. > 5 Tahun & 26 & 54,2 & 27 & 56,3 \\
\hline
\end{tabular}

(Puskesmas Kota Pekanbaru, 2019)

Berdasarkan tabel 1 menunjukkan karakteristik responden terdiri dari distribusi umur perawat sebagian besar dewasa awal (26-35 tahun) yaitu kelompok eksperimen sebanyak 23 orang $(47,9 \%)$ dan kelompok kontrol sebanyak 26 orang $(54,2 \%)$. Jenis kelamin pada sebagian besar perempuan yaitu kelompok eksperimen sebanyak 27 orang $(56,3 \%)$ dan kelompok kontrol sebanyak 25 orang $(52,1 \%)$. Pendidikan pada kelompok eksperimen sebagian besar jenjang S.1 yaitu sebanyak 26 orang $(54,2 \%)$ sedangkan pada kelompok kontrol setengahnya jenjang D.3 sebanyak 24 orang (50,0\%). Masa kerja sebagian besar besar > 5 tahun yaitu kelompok eksperimen sebanyak 26 orang $(54,2 \%)$ dan kelompok kontrol sebanyak 27 orang $(56,3 \%)$. 
Tabel. 2

Distribusi Rerata Perbedaan Pengetahuan Perawat tentang Dokumentasi Keperawatan Sebelum dan Sesudah Intervensi dan Pengukuran ke-1, dan Pengukuran ke-2

Kelompok Eksperimen dan Kelompok Kontrol $(\mathrm{N}=96)$

\begin{tabular}{lccccc}
\hline \multicolumn{1}{c}{ Pengetahuan Perawat } & $\mathrm{N}$ & Mean & SD & $95 \%$ CI & p Value \\
\hline Intervensi & & & & & \\
Pretest-P1 & 48 & 5,95 & 4,74 & $7,33-4,58$ & 0,000 \\
P1 - P2 & 48 & 2,18 & 2,66 & $2,96-1,41$ & 0,000 \\
\hline Kontrol & & & & & \\
Pretest-P1 & 48 & 0,60 & 1,18 & $0,94-0,26$ & 0,001 \\
P1 - P2 & 48 & 0,70 & 1,44 & $1,12-0,28$ & 0,001 \\
\hline
\end{tabular}

(Puskesmas Kota Pekanbaru, 2019)

Berdasarkan tabel 2 menunjukkan bahwa perbedaan pengukuran pengetahuan perawat tentang dokumentasi keperawatan pada kelompok intervensi sebelum dilakukan intervensi dengan pengukuran postes- 1 didapatkan nilai $p$ Value $=0,000<\alpha=0,05$ artinya ada perbedaan pengetahuan perawat tentang dokumentasi keperawatan antara sebelum dengan setelah pengukuran postest-1 dilakukan intervensi model ANNISA dan pengukuran pengetahuan perawat tentang dokumentasi keperawatan postest-1 dengan postest- 2 didapatkan nilai $p$ Value $=0,000<\alpha=0,05$ artinya ada perbedaan pengetahuan perawat tentang dokumentasi keperawatan antara setelah pengukuran postest-1 dengan pengukuran postest-2 setelah dilakukan intervensi model ANNISA. Sedangkan perbedaan pengukuran pengetahuan perawat tentang dokumentasi keperawatan pada kelompok kontrol sebelum dan setelah pengukuran postest-1 didapatkan nilai $p$ Value $=$ $0,001<\alpha=0,05$ artinya ada perbedaan pengetahun perawat tentang dokumentasi keperawatan antara sebelum dan setelah pengukuran pada kelompok kontrol, dan pengukuran postest- 1 dengan postest- 2 didapatkan nilai $p$ Value $=0,001<\alpha=0,05$ artinya ada perbedaan pengetahuan perawat tentang dokumentasi keperawatan antara setelah pengukuran postest-1 dengan pengukuran postest-2 pada kelompok kontrol.

Tabel. 3

Distribusi Nilai Rerata Pengetahuan Perawat tentang Dokumentasi Keperawatan antara Kelompok Intervensi dan Kelompok Kontrol pada Pengukuran Pretest, Postest-1 dan Postest-2 Setelah Dilakukan Pengembangan Model ANNISA ( $=96)$

\begin{tabular}{ccccccc}
\hline Pengukuran & Kelompok & $\mathrm{n}$ & Mean & SD & $\begin{array}{c}\text { CI } \\
95 \%\end{array}$ & P Value \\
\hline Pretest & Intervensi & 48 & 24,6 & 4,96 & $2,15-2,07$ & 0,969 \\
& Kontrol & 48 & 24,7 & 5,47 & & \\
Postest-1 & Intervensi & 48 & 30,6 & 4,76 & $3,28-7,33$ & 0,000 \\
& Kontrol & 48 & 25,3 & 5,22 & & \\
Postest-2 & Intervensi & 48 & 32,8 & 3,64 & \multirow{2}{*}{0,000} \\
& Kontrol & 48 & 26,0 & 5,27 & $4,95-63$ & 0,000 \\
\hline
\end{tabular}

(Puskesmas Kota Pekanbaru, 2019)

Berdasarkan tabel 3 menunjukkan bahwa perbedaan pengukuran pengetahuan perawat tentang dokumentasi keperawatan pretest didapatkan nilai $\mathrm{p}$ value $=0,969>\alpha$ $=0,05$ artinya tidak ada perbedaan pengetahuan perawat tentang dokumentasi keperawatan antara kelompok intervensi dan kelompok kontrol sebelum dilakukan intervensi pengembangan model ANNISA di Puskesmas Kota Pekanbaru. Pengukuran 
pengetahuan perawat tentang dokumentasi keperawatan postest -1 didapatkan nilai $\mathrm{p}$ value $=0,000<\alpha=0,05$ artinya ada perbedaan pengetahuan perawat tentang dokumentasi keperawatan antara kelompok intervensi dan kelompok kontrol sebelum dilakukan intervensi pengembangan model ANNISA di Puskesmas Kota Pekanbaru. Pengukuran pengetahuan perawat tentang dokumentasi keperawatan postest-2 didapatkan nilai $\mathrm{p}$ value $=0,000<\alpha=0,05$ artinya ada perbedaan pengetahuan perawat tentang antara kelompok intervensi dan kelompok kontrol sebelum dilakukan intervensi pengembangan model ANNISA di Puskesmas Kota Pekanbaru.

Tabel. 4

Analisis Multivariat Pengetahuan Perawat tentang Dokumentasi Keperawatan pada Kelompok Intervensi dan Kontrol Setelah Dilakukan Pengembangan Model ANNISA di (N=96)

\begin{tabular}{|c|c|c|c|c|c|}
\hline Variabel & Kelompok & $\mathrm{N}$ & Mean & SD & $\mathrm{p}$ Value \\
\hline Pretest & $\begin{array}{c}\text { Intervensi } \\
\text { Kontrol }\end{array}$ & $\begin{array}{l}48 \\
48\end{array}$ & 24,7 & 5,19 & \\
\hline Postest-1 & $\begin{array}{c}\text { Intervensi } \\
\text { Kontrol }\end{array}$ & $\begin{array}{l}48 \\
48\end{array}$ & 27,9 & 5,64 & 0,000 \\
\hline Postest-2 & $\begin{array}{c}\text { Intervensi } \\
\text { Kontrol }\end{array}$ & $\begin{array}{l}48 \\
48\end{array}$ & 29,4 & 5,65 & \\
\hline
\end{tabular}

(Puskesmas Kota Pekanbaru, 2019)

Berdasarkan tabel 4 menunjukkan hasil uji statistik GLM-RM didapatkan bahwa nilai $\mathrm{p}$ Value $=0,000$ artinya ada peningkatan perbedaan pengetahuan perawat tentang dokumentasi keperawatan dari pengukuran pretest, pengukuran postest-1 dan pengukuran postest- 2 setelah dilakukan pengembangan model ANNISA pada kelompok intervensi maupun kelompok kontrol.

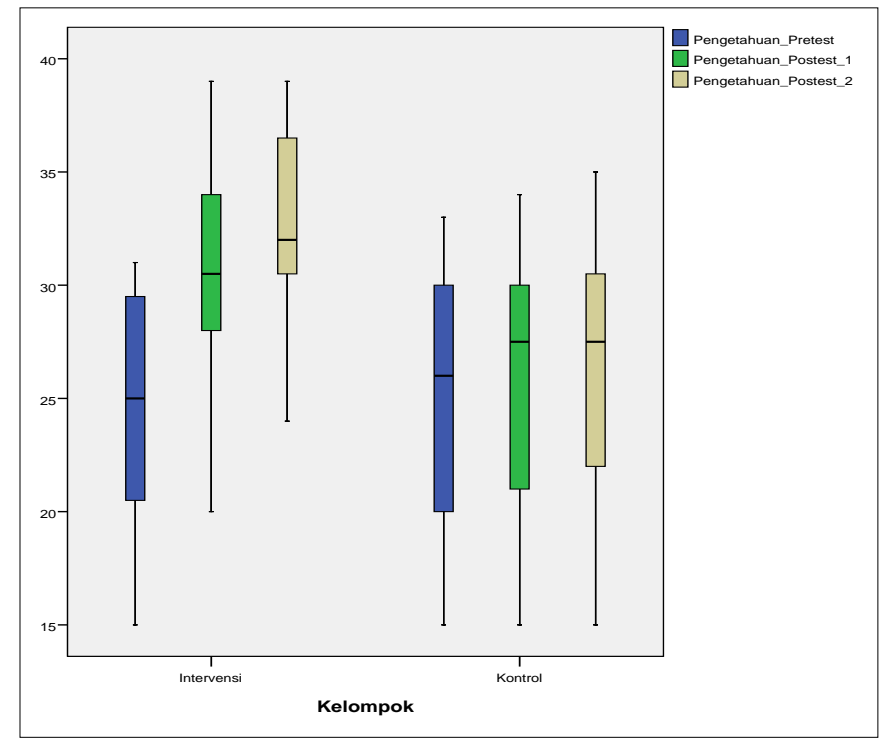

Gambar. 1

Boxplot Peningkatan Nilai Rerata Pengetahuan Perawat tentang Dokumentasi Keperawatan Berdasarkan pada Saat Pengukuran Pretest, Postest-1 dan Postest-2 Setelah Intervensi 
Berdasarkan gambar 1 menunjukkan bahwa boxplots peningkatan pengetahuan terdapat perbedaan distribusi peningkatan rerata pada kelompok intervensi dan pada kelompok kontrol dari pengukuran Pretest, Postest-1 dan Postest-2. Hal ini menunjukkan bahwa efek terhadap skor pengetahuan perawat tentang Dokumentasi Keperawatan terlihat jelas pada pengukuran ke dua dan pengukuran ke tiga pada kelompok intervensi maupun kelompok kontrol.

\section{PEMBAHASAN}

\section{Perbedaan Pengetahuan Perawat tentang Dokumentasi Keperawatan Sebelum dan Sesudah Penggunaan Aplikasi ANNISA}

Pengembangan ANNISA ini menghasilkan prototipe terdiri dari model sistem, diagram alur, diagram konteks, dan hierarki input, proses, dan output. Sistem ini memiliki dua dekomposisi, dokumentasi asuhan keperawatan dan fungsi manajemen keperawatan. Sistem ini menghubungkan NANDA-I, NIC, dan NOC untuk membantu perawat dalam melakukan proses keperawatan. Perawat menemukan hubungan ini bermanfaat untuk memiliki dokumentasi keperawatan yang lengkap, berkelanjutan, dan berkualitas. Terminologi keperawatan standar (SNT) memainkan peran penting dalam menggambarkan dan mendefinisikan asuhan keperawatan. SNT dapat memberikan informasi penting untuk pengembangan perencanaan asuhan keperawatan elektronik dalam catatan kesehatan elektronik sebagai bagian dari asuhan keperawatan (Olatubi et al., 2019).

Penelitian ini sejalan dengan penelitian yang dilakukan oleh (Karp et al., 2019) dimana penggunaan aplikasi elektronik health record (HER) dapat meningkatkan pengetahuan perawat tentang dokumentasi keperawatan ( $p$ Value $=0,001$ ). Hal ini memberikan gambaran bahwa penggunaan model aplikasi pada bentuk EHR dalam praktik dokumentasi keperawatan akan meningkatkan pengetahuan tentang dokumentasi keperawatan baik di rumah sakit maupun di tingkat pelayanan primer. Peningkatan pengetahuan tentang dokumentasi keperawatan setelah dilakukan ANNISA juga dapat disebabkan karena adanya modul dan pedoman yang telah disusun sebagai referensi bagi perawat dalam melakukan dokumentasi keperawatan. Dalam pedoman yang telah disusun tersebut sudah memenuhi aspek pengetahuan perawat, terminologi NNN Linkage yang digunakan untuk mendukung peningkatan pengetahuan perawat dalam pendokumentasian asuhan keperawatan yang akan dilakukan.

Peneliti berasumsi bahwa kefektifan penggunaan Aplikasi ANNISA harus didukung dengan karakteristik perawat yang memadai pula. Aspek peningkatan pengalaman perawat, pengetahuan perawat tentang dokumentasi dan nomenklatur NNN Linkage, pengaturan beban kerja perawat lebih efisien akan berdampak langsung terhadap penggunaan aplikasi ANNISA. Tentunya dampak tersebut akan terus dapat ditingkatkan melalui proses peningkatan kemampuan penggunaan aplikasi ANNISA melalui pelatihan dan pembelajaran terus menerus oleh perawat sehingga tujuan akhir dari dokumentasi keperawatan yaitu peningkatan pengetahuan tentang dokumentasi keperawatan dapat terlaksana di Puskesmas Kota Pekanbaru.

Penerapan NANDA-I, NIC, dan NOC dalam pendokumentasian proses keperawatan merupakan salah satu bentuk penggunaan standar bahasa keperawatan (standard nursing language) dalam proses keperawatan. Hasil penelitian ini menunjukkan bahwa ada perbedaan tingkat pengetaahuan perawat tentang dokumentasi sebelum dan sesudah penerapan standar bahasa keperawatan yang berbentuk NANDA-I, NIC, dan NOC. 


\section{Perbedaan Pengetahuan Perawat tentang Dokumentasi Keperawatan Sebelum dan Sesudah Penggunaan Aplikasi ANNISA pada Kelompok Intervensi dan Kelompok Kontrol}

Faktor yang berkontribusi terhadap peningkatan pengetahuan perawat tentang dokumentasi keperawatan terdiri dari karakteristik perawat, dukungan teknis, kebijakan, dan dukungan kepemimpinan untuk menciptakan dan mempertahankan perubahan dari dokumentasi keperawatan berbasis teknologi menjadi informasi. Faktor motivasi perawat, beban kerja yang tinggi, dan alokasi waktu yang rendah untuk menyelesaikan dokumentasi keperawatan memang beberapa faktor yang menghambat perawat dalam melakukan dokumentasi keperawatan yang tepat (Giacomo \& Santin, 2019). Sementara itu, dukungan dari pengguna, informasi, teknologi, dan organisasi juga dapat mempengaruhi efektivitas implementasi sistem. Studi saat ini ditemukan konsisten dengan temuan sebelumnya (Kamil et al., 2018).

Pada beberapa hasil penelitian menunjukkan bahwa kelompok kontrol juga memiliki peningkatan pengetahuan perawat tentang dokumentasi keperawatan (Karp et al., 2019). Hal ini bisa disebabkan karena faktor pada saat proses penelitian perawat pada kelompok kontrol juga ikut berpartisipasi dalam proses pelatihan yang dilakukan oleh peneliti. Selain itu kelompok responden memungkinkan perawat berbagi pengalaman dan informasi tentang pelaksanaan dokumentasi keperawatan yang dilakukan. Faktor lain juga mendukung peningkatan yang tidak siginifikan pada kelompok kontrol juga bisa disebabkan karena perawat melakukan kajian kepustakaan tentang NNN Linkage dimana pada saat sosialisasi, peneliti telah memberikan satu buku referensi tentang pedoman asuhan keperawatan komunitas yang menggunakan terminologi NNN Linkage (Giacomo \& Santin, 2019).

Disamping itu pada kelompok kontrol peneliti juga mengarahkan perawat agar tetap melakukan proses pelaksanaan dokumentasi keperawatan akan tetapi dokumentasi keperawatan yang dilakukan masih berbasis kertas. Penelitian yang dilakukan oleh (McNicol et al., 2018) yang menunjukkan bahwa Analisis data menemukan perbedaan yang signifikan dalam kualitas dokumentasi keperawatan di dua rumah sakit baik sebelum dan sesudah penerapan sistem EHR. Perbedaan antara kelompok intervensi dan kelompok kontrol tidak terlepas dari ketersediaan sarana-prasarana yang dimiliki oleh puskesmas dalam melaksanakan dokumentasi keperawatan. Kebutuhan perawat dalam penggunaan dokumentasi berbasis komputer menyebabkan kendala bagi perawat untuk meningkatkan pengetahuan perawat tentang dokumentasi keperawatan di Puskesmas.

Peneliti berasumsi bahwa perbedaan antara kelompok intervensi dan kelompok kontrol terhadap pengetahuan perawat tentang dokumentasi keperawatan disebabkan karena penggunaan sistem aplikasi ANNISA sudah sangat membantu dalam proses dokumentasi keperawatan. Sedangkan kelompok kontrol masih hanya menggunakan paper based sehingga puskesmas perlu mempertimbangkan kesediaan sarana penunjang bagi kelompok kontrol juga untuk menyediakan fasilitas penggunaan aplikasi ANNISA dalam pelaksanaan dokumentasi keperawatan.

\section{Analisis Multivariat terhadap Pengetahuan Perawat pada Kelompok Kontrol dan Kelompok Intervensi di Puskesmas Kota Pekanbaru}

Penggunaan aplikasi ANNISA dari waktu pengukuran postest-1 hingga postest-2 secara signifikan menimbulkan efek bagi pengetahuan perawat tentang dokumentasi keperawatan yang dilakukan oleh perawat. Meskipun peningkatan proses dokumentasi terjadi, Saputra \& Arif (2019) menyarankan bahwa ada perlu dikaji kekurangan dalam 
isi EHR yang membatasi kemampuan untuk meninjau prosedur keperawatan dan data kinerja. Pernyataan tersebut dikuatkan dengan hasil penelitian yang menunjukkan bahwa walaupun penggunaan aplikasi ANNISA dilaksanakan akan tetapi penggunaan paper based juga mengalami peningkatan walaupun tidak signifikan. Proses ini menjadi pertimbangan peneliti untuk lebih meningkatkan peran penggunaan aplikasi ANNISA dalam pelaksanan dokumentasi keperawatan yang dilakukan di puskesmas.

Hasil penelitian juga menggambarkan perawat merasa sangat terbantu dengan implementasi dokumentasi EHR dan karenanya waktu yang dihabiskan untuk proses pencatatan mengurangi waktu yang tersedia untuk prosedur perawatan pasien langsung. Temuan ini mengarah pada kesimpulan bahwa tidak ada perubahan yang bermanfaat dalam prosedur perawatan pasien, alur kerja, dan waktu yang dihabiskan untuk dokumentasi, dan akibatnya tidak ada perubahan dalam kualitas dokumentasi sehingga menimbulkan kekhawatiran bagi perawat yang menggunakan dokumentasi berbasis kertas. Proses inilah yang menghasilkan keinginan dari perawat untuk melakukan dokumentasi keperawatan dengan metode aplikasi ANNISA.

Penelitian yang dilakukan oleh (Karp et al., 2019) menunjukkan ada peningkatan dari pengukuran pengetahuan perawat tentang dokumentasi keperawatan dari pengukuran-1 ke pengukuran-2 dengan nilai signifikan peningkatan $p$ Value $=0,001$. Peneliti berasumsi bahwa proses peningkatan dari waktu pengukuran ke-1 dan ke-2 menjadi indikator bahwa, proses peningkatan pengetahuan perawat tentang dokumentasi keperawatan dapat terlaksana apabila penggunaan aplikasi ANNISA dapat dilakukan secara terus menerus. Untuk itu puskesmas sudah harus menyusun kebijakan dalam penggunaan aplikasi ANNISA di puskesmas guna mendukung perawat dalam melaksanakan pendokumentasian asuhan keperawatan di Puskesmas Kota Pekanbaru.

\section{SIMPULAN}

Terdapat perbedaan pengetahuan perawat tentang dokumentasi keperawatan sebelum, postest-1 dan postest-2 setelah dilakukan penggunaan aplikasi ANNISA di Puskesmas Kota Pekanbaru. Selanjutnya terdapat perbedaan pengetahuan perawat tentang dokumentasi keperawatan sebelum, postest-1 dan postest-2 setelah dilakukan penggunaan aplikasi ANNISA pada kelompok intervensi dan kelompok kontrol di Puskesmas Kota Pekanbaru.

\section{SARAN}

Diharapkan pihak Dinas Kesehatan Kota Pekanbaru dan Kepala Puskesmas Kota Pekanbaru agar mempertimbangkan penggunaan model pendokumentasian keperawatan berbasis komputerisasi dengan berbagai aplikasi seperti aplikasi ANNISA agar dapat meningkatkan pengetahuan perawat tentang dokumentasi keperawatan di tingkat pelayanan primer dan puskesmas.

\section{DAFTAR PUSTAKA}

Cassano, C. (2018). Nursing Informatics Progression Theory: (NIPT) - The 4A's of Adaptability. Nursing \& Primary Care, 2(1), 1-6. https://doi.org/10.33425/26399474.1054

Chae, S., Oh, H., \& Moorhead, S. (2020). Effectiveness of Nursing Interventions using Standardized Nursing Terminologies: An Integrative Review. Western Journal of Nursing Research. https://doi.org/10.1177/0193945919900488 
Chand, S., \& Sarin, J. (2019). Confident or Confused: Nurses' Perception and Acceptability of Electronic Nursing Documentation. International Journal Fo Health Science and Research, 9(10), 197-203

Giacomo, P. D., \& Santin, C. (2019). The Implementation of Electronic Nursing Documentation with NANDA-I , NOC and NIC in a Psychosocial Rehabilitation Residential Center, in Italy. Research Gate, April, 0-5

Kamil, H., Rachmah, R., \& Wardani, E. (2018). What is the Problem with Nursing Documentation? Perspective of Indonesian nurses. International Journal of Africa Nursing Sciences, 9, 111-114. https://doi.org/10.1016/j.ijans.2018.09.002

Karp, E. L., Freeman, R., Simpson, K. N., \& Simpson, A. N. (2019). Changes in Efficiency and Quality of Nursing Electronic Health Record Documentation after Implementation of an Admission Patient History Essential Data Set. CIN Computers Informatics Nursing, 37(5), 260-265. https://doi.org/10.1097/CIN.0000000000000516

Lee, S., Jeon, M. Y., \& Kim, E. O. (2019). Implementation of Structured Documentation and Standard Nursing Statements: Perceptions of Nurses in Acute Care Settings. CIN-Computers Informatics Nursing, 37(5), 266-275. https://doi.org/10.1097/CIN.0000000000000510

McNicol, L., Hutchinson, A. F., Wood, B., Botti, M., \& Redley, B. (2018). An Exploration of Patients' Experience of Nurses' Use of Point-of-Care Information Technology in Acute Care. Patient Experience Journal, 5(1), 76-89. https://doi.org/10.35680/2372-0247.1213

Olatubi, M. I., Oyediran, O. O., Faremi, F. A., \& Salau, O. R. (2019). Knowledge, Perception, and Utilization of Standardized Nursing Language (SNL) (NNN) among Nurses in Three Selected Hospitals in Ondo State, Nigeria. International Journal of Nursing Knowledge, 30(1), 43-48. https://doi.org/10.1111/20473095.12197

Omonigho, O. P. (2019). Evaluation of the Use of NANDA-I Nursing Diagnoses, Nursing Outcome Classification and Nursing Intervention Classification for Documentation of Care in Primary Health Centres, Ijebu Ode. Texila International Journal of Nursing, 5(1), 25-37. https://doi.org/10.21522/tijnr.2015.05.01.art003

Oreofe, R. N., \& Oyenike, R. N. (2018). Transforming Practice Through Nursing Innovative Patient Centered Care: Standardized Nursing Languages. International Journal of Caring Sciences, 11(2), 1319-1322

Padila, P., Lina, L. F., Febriawati, H., Agustina, B., \& Yanuarti, R. (2018). Home Visit Berbasis Sistem Informasi Manajemen Telenursing. Jurnal Keperawatan Silampari, 2(1), 217-235. https://doi.org/10.31539/jks.v2i1.305

Peltonen, L.-M., Pruinelli, L., Ronquillo, C., Nibber, R., Peresmitre, E. L., Block, L., Deforest, H., Lewis, A., Alhuwail, D., Ali, S., Badger, M. K., Eler, G. J., Georgsson, M., Islam, T., Jeon, E., Jung, H., Kuo, C. H., Sarmiento, R. F. R., Sommer, J. A., \& Topaz, M. (2019). The current State of Nursing Informatics An International Cross-Sectional Survey. Finnish Journal of eHealth and eWelfare, 11(3), 220-231. https://doi.org/10.23996/fjhw.77584

Pratama, T. W. Y., Tamtomo, D., \& Sulaeman, E. S. (2018). Factors Associated with the Completeness of Inpatient Medical Record Filling in Dr. R Sosodoro Djatikoesoemo, Bojonegoro, East Java. Journal of Health Policy and Management, 3(1), 1-10. https://doi.org/10.26911/thejhpm.2018.03.01.01 
Rojjanasrirat, W. (2018). Evidence-Based Practice Competencies among Online Graduate Nursing Students. Journal of Nursing \& Care, 7, 4172. https://doi.org/10.4172/2167-1168-c4-073

Salameh, B., Eddy, L. L., Batran, A., Hijaz, A., \& Jaser, S. (2019). Nurses' Attitudes Toward the Use of an Electronic Health Information System in a Developing Country. Sage Open Nursing, 5, 1-8. https://doi.org/10.1177/2377960819843711

Saputra, A. (2018). The Influence of Nursing Care Documenting Behavior to the Completeness of Nursing Care Documentation at Hospital X. Jurnal Medicoeticolegal dan Manajemen Rumah Sakit, 7(2), 170-177. https://doi.org/10.18196/jmmr.7270

Saputra, C., \& Arif, Y. (2019). Nursing Informatics System in Health Care Delivery. KnE Publisher: Panihc Confrence, 2019, 38-46. https://doi.org/10.18502/kls.v4i10.3827

Saputra, C., Arif, Y., \& Yeni, F. (2019). Faktor yang Berhubungan dengan Kualitas dan Kelengkapan Dokumentasi Keperawatan. Jurnal Ilmiah Permas: Jurnal Ilmiah STIKes Kendal, 9(3), 187-196

Saraswasta, I. W. G., \& Hariyati, R. T. S. (2019). The Implementation of Electronic based Nursing Care Documentation to EFETEC; A Literature Review. International Journal of Nursing and Health Services (IJNHS), 1(2), 19-31. https://doi.org/10.35654/ijnhs.v1i2.23 